\title{
Pelvic floor muscle training in spinal cord injury and its impact on neurogenic detrusor over-activity and incontinence
}

\author{
N Vásquez ${ }^{1}$, SL Knight ${ }^{1,2}$, J Susser ${ }^{1}, \mathrm{~A} \mathrm{Gall}^{1}, \mathrm{PH}$ Ellaway $^{1,3}$ and MD Craggs ${ }^{1,2}$
}

Study design: Two case studies.

Objectives: To determine whether 6 weeks of regular pelvic floor muscle training (PFMT) can improve the strength and endurance of voluntary contractions in incomplete spinal cord injury and reduce neurogenic detrusor over-activity (NDO) and incontinence.

Setting: The London Spinal Cord Injury Centre, Stanmore, London, UK.

Methods: A 6-week programme of PFMT was conducted in two male subjects with stable supra-sacral motor incomplete (AIS C and D) spinal cord injuries. Clinical evaluations before and after training comprised measures of strength and endurance of voluntary pelvic floor contractions both objectively by anal canal-pressure measurements and subjectively using the modified Oxford grading system. NDO was determined by standard urodynamic tests of bladder function and incontinence measured by the International Consultation on Incontinence Questionnaire-Urology.

Results: Both subjects improved the strength and endurance of their pelvic floor muscle contractions by over $100 \%$ at the end of training. After training, Subject 1 (AIS D) was able to reduce bladder pressure during over-activity almost completely by voluntarily contracting the pelvic floor muscles. Subject 2 (AIS C) achieved a lesser reduction overall after training. Continence improved only in subject 1 .

Conclusion: These case studies provide evidence that a 6-week programme of PFMT may have a beneficial effect on promoting voluntary control of NDO and reduce incontinence in selected cases with a motor incomplete spinal cord lesion.

Spinal Cord (2015) 53, 887-889; doi:10.1038/sc.2015.121; published online 4 August 2015

\section{INTRODUCTION}

Incontinence remains a priority problem for many people with spinal cord injury ${ }^{1}$ despite various current treatments including conservative therapies. ${ }^{2}$ Control of the bladder, sphincter and pelvic floor muscles (PFM) relies on the integrity of bulbo-spinal, cortico-spinal and lumbo-sacral reflex pathways. Following a motor incomplete spinal cord injury (iSCI), voluntary control of the PFM including the striated sphincters significantly weakens, neurogenic detrusor over-activity (NDO), detrusor sphincter dyssynergia and incontinence emerge reducing quality of life. Although PFM training (PFMT) has been shown to be effective in non-SCI patients with lower urinary tract symptoms, for example, by reducing stress incontinence and suppressing bladder over-activity, ${ }^{3}$ it appears not to have been tested as a potential therapy in iSCI. Therefore the aim of these two case studies was to determine whether 6 weeks of regular PFMT could improve the strength and endurance of voluntary PFM contractions in iSCI so as to suppress NDO and reduce incontinence. A positive outcome may then justify a pilot study with a larger cohort of iSCI subjects presenting with preserved sensorimotor pathways of the sphincters and PFMs.

\section{MATERIALS AND METHODS \\ Participants}

A 6-week programme of regular PFMT with clinical assessments before and after was conducted in two male subjects presenting with chronic-stable iSCI, NDO and incontinence.

Local research ethics committee approval was obtained (REC Reference No. 11/LO/0601. Amendment: 19 June 2014) through the UK Integrated Research Application System (IRAS_-Project ID: 44315). Informed consent was obtained from each subject.

Subject 1, aged 53 years with iSCI at C3 level acquired at the age of 37 years was assessed AIS (American Spinal Injury Association (ASIA) Impairment Scale (AIS) grade D (motor incomplete). Subject 2 aged 64 years with an iSCI at T11 level acquired at the age of 42 years was assessed as AIS grade C (motor incomplete). Subject 1 did not take anti-muscarinic medication and voided on urge, whereas Subject 2 was on anti-muscarinic drugs and clean intermittent catheterisation for bladder emptying. Bladder medication was stopped 5 days before each cystometric test but resumed immediately afterwards.

\section{Intervention}

The PFMT programme was explained verbally and given to each subject in writing (See Supplementary Information). The programme consisted of up to 40 PFM contractions divided into 4 sets (3 sets of prolonged contractions and

\footnotetext{
${ }^{1}$ London Spinal Cord Injury Centre, Royal National Orthopaedic Hospital, London, UK; ${ }^{2}$ Division of Surgery and Interventional Science, University College London, London, UK and ${ }^{3}$ Department of Medicine, Division of Brain Sciences, Imperial College London, London, UK

Correspondence: N Vásquez, Clinical Research Physiotherapist, London Spinal Cord Injury Centre, Royal National Orthopaedic Hospital, Brockley Hill, Stanmore, London HA7 4LP, UK.

E-mail: natalia.vasquez@rnoh.nhs.uk

Received 3 March 2015; revised 9 May 2015; accepted 29 May 2015; published online 4 August 2015
} 


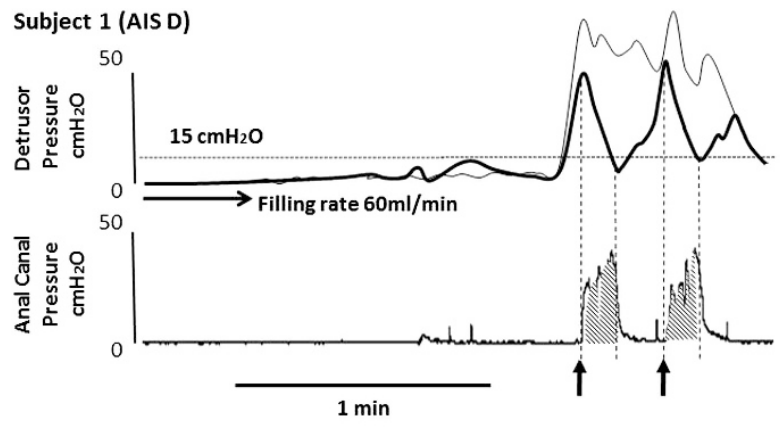

Subject 2 (AIS C)

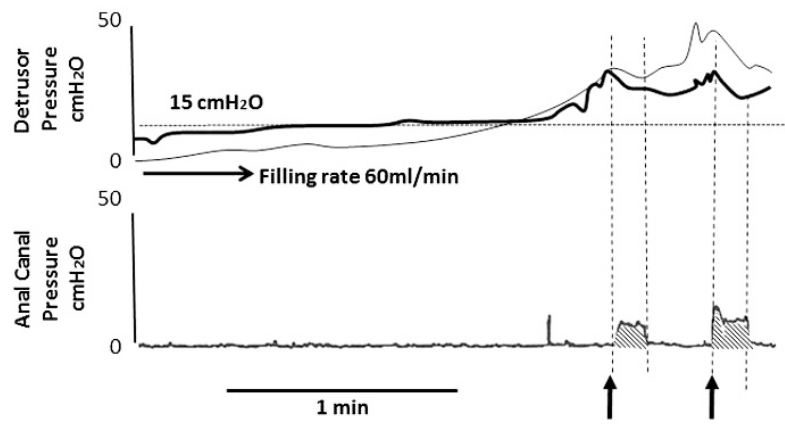

Figure 1 Representative examples from Subjects 1 and 2 of a control cystometry showing NDO (fine line) and the suppressive effect on this neurogenic over-activity (thick line) of two PFM contractions performed when the bladder pressure reached levels of $>15 \mathrm{~cm} \mathrm{H} \mathrm{H}_{2} \mathrm{O}$. Objective measures of PFM strength and endurance were determined from the hatched areas under the curve (AUC_-equivalent to anal canal-pressure fluctuations multiplied by time over $10 \mathrm{~s})$
1 set of short contractions). Subjects were asked to follow the programme three times daily in different positions; lying down, sitting and standing if possible. Subjects were also encouraged to perform PFM contractions at other times as soon as they felt a bladder urge. Subjects were asked to fill in a PFMT diary and the continence physiotherapist contacted the subjects each week to ensure compliance and motivation.

\section{Outcome measures}

Objective clinical evaluations before and after PFMT comprised (i) measures of strength and endurance of voluntary PFM contractions obtained from anal canal-pressure changes over $10 \mathrm{~s}$ of effort and (ii) the effect of those contractions on changes to detrusor pressure during NDO using standard cystometry following retrograde bladder filling at $60 \mathrm{ml} \mathrm{min}^{-1}$ with sterile saline (see Figure 1).

Subjective evaluations of PFM contractions were assessed by the physiotherapist using the Modified Oxford grading system (6 point scale). ${ }^{4}$ Urinary incontinence was assessed by each subject using the ICIQ (International Consultation on Incontinence)-UI (Urinary Incontinence) short form questionnaire (a score of 21 was defined as worst incontinence) before and after the PFMT.

\section{RESULTS}

Comparing before and after PFMT the following results were obtained.

Subject 1 improved strength and endurance by $118 \%$ and Subject 2 by $144 \%$ (see Figure 2a). The Modified Oxford score also showed improvements of $17 \%$ in both subjects. In Subject 1 PFM contractions suppressed NDO by $81 \%$ and in Subject 2 the suppression was $16 \%$ (see Figure 2b). The ICIQ-UI score showed reduced incontinence in Subject 1 of $10 \%$ whereas Subject 2 showed no change. All results are summarised in Table 1.

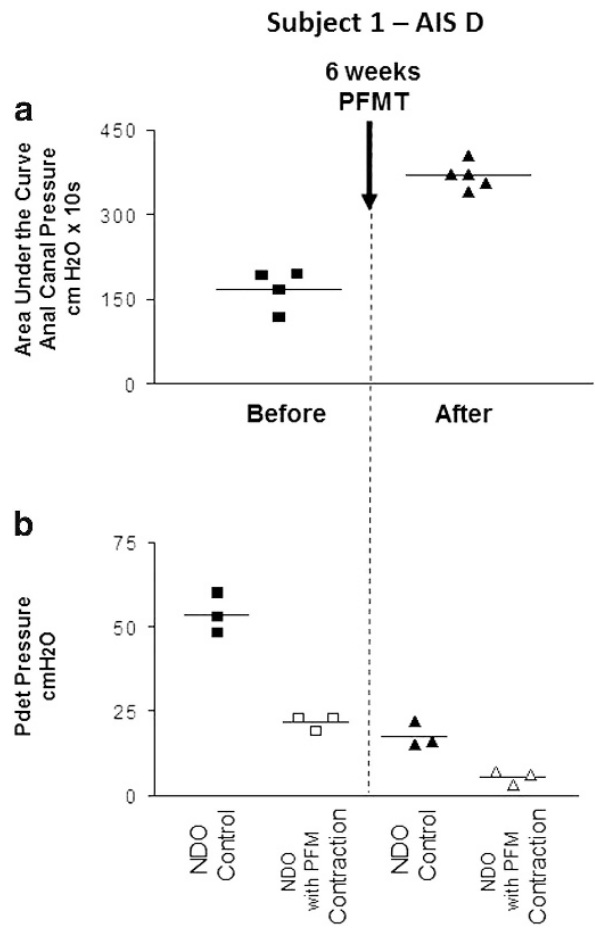

Before

After

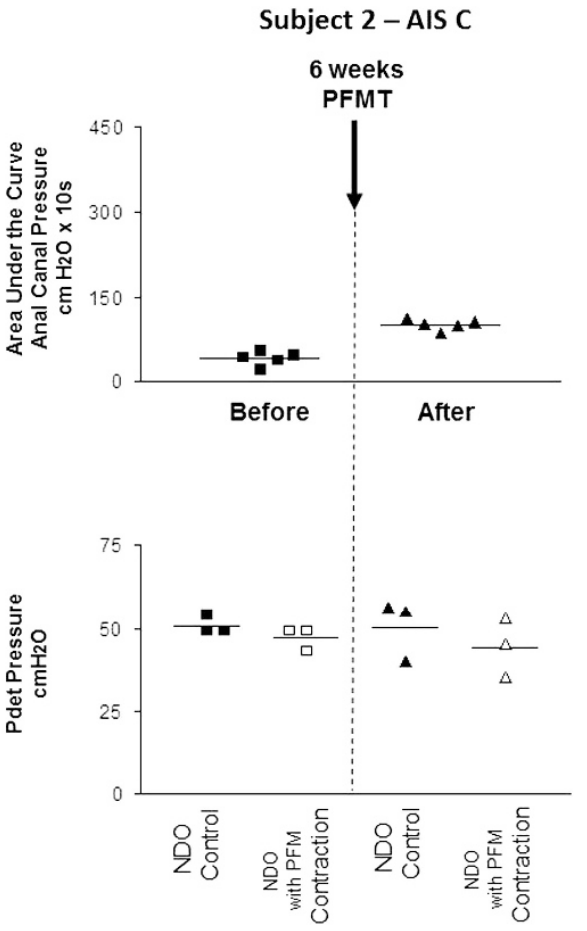

Before
After

Figure 2 Effect of 6 weeks of PFMT in each Subject. (a) Increase in PFM strength and endurance and (b) on suppression of NDO during $10 \mathrm{~s}$ of PFM contractions. 
Table 1 Outcomes of study showing the objective measures (PFM and NDO) and subjective measures (Oxford and ICIQ-UI) for each subject before and after PFMT, comparisons and overall changes

\begin{tabular}{|c|c|c|c|c|c|c|c|c|}
\hline & \multicolumn{4}{|c|}{ Subject 1 (AIS D) } & \multicolumn{4}{|c|}{ Subject 2 (AIS C) } \\
\hline & $\begin{array}{l}\text { Modified Oxford } \\
\text { Score (maximum } \\
\text { improvement }=6 \text { ) }\end{array}$ & $\begin{array}{l}\text { PFM increase } \\
\text { AUC (cm of } \\
\left.\mathrm{H}_{2} \mathrm{O} \times 10 \mathrm{~s}\right)\end{array}$ & $\begin{array}{l}\text { NDO suppression } \\
\text { (change in detrusor } \\
\text { pressure }-\mathrm{cm} \text { of } \mathrm{H}_{2} \mathrm{O} \text { ) }\end{array}$ & $\begin{array}{c}\text { ICIQ-UI Score } \\
\text { (maximum } \\
\text { incontinence }=21 \text { ) }\end{array}$ & $\begin{array}{l}\text { Modified Oxford } \\
\text { Score (maximum } \\
\text { improvement }=6 \text { ) }\end{array}$ & $\begin{array}{l}\text { PFM increase } \\
\text { AUC (cm of } \\
\left.\mathrm{H}_{2} \mathrm{O} \times 10 \mathrm{~s}\right)\end{array}$ & $\begin{array}{l}\text { NDO suppression } \\
\text { (change in detrusor } \\
\text { pressure- }-\mathrm{cm} \text { of } \mathrm{H}_{2} \mathrm{O} \text { ) }\end{array}$ & $\begin{array}{c}I C / Q-U I \text { Score } \\
\text { (maximum } \\
\text { incontinence }=21)\end{array}$ \\
\hline $\begin{array}{l}\text { Before } \\
\text { PFMT }\end{array}$ & $2 / 6$ & 170 & 31 & $6 / 21$ & $1 / 6$ & 40 & 3 & $14 / 21$ \\
\hline $\begin{array}{l}\text { After } \\
\text { PFMT }\end{array}$ & $3 / 6$ & 370 & 13 & $4 / 21$ & $2 / 6$ & 105 & 5 & $14 / 21$ \\
\hline $\begin{array}{l}\text { Overall } \\
\text { change }\end{array}$ & $17 \%$ & $118 \%$ & $81 \%$ & $10 \%$ & $17 \%$ & $144 \%$ & $16 \%$ & $0 \%$ \\
\hline
\end{tabular}

Abbreviations: AIS, American Spinal Injury Association Impairment Scale; AUC, area under the curve; ICIQ-UI, International Consultation on Incontinence-Urinary Incontinence; NDO, neurogenic detrusor over-activity; Oxford, modified Oxford grading system; PFM, pelvic floor muscle; PFMT, PFM training.

\section{DISCUSSION AND CONCLUSIONS}

One of these two case studies (Subject 1; AIS D), provided good evidence that a relatively short programme of PFMT can have a beneficial effect on restoring PFM voluntary control over NDO and reducing incontinence in selected individuals with a motor incomplete SCI. However, although Subject 1 showed excellent voluntary control over the suppression of bladder over-activity to improve continence, Subject 2 (AIS C) performed much less well on both suppressing the over-activity and reducing incontinence despite a substantial benefit in percentage terms of PFMT on PFM contractions. Interestingly, both subjects presented with comparable levels of neurogenic detrusor activity suggesting similar autonomic dysfunction consistent with an upper motor neuron lesion.

More recent evidence by others has suggested that not only might a longer programme of PFMT (up to 16 weeks) may yield better results, ${ }^{5}$ but that further improvements be achieved by adding biofeedback and electrical stimulation. ${ }^{3}$

Some positive outcomes of the present study suggest the need for a pilot study of PFMT in a larger cohort of subjects. Such a study may then lead to a more cost-effective management for urinary incontinence in selected persons presenting with a motor iSCI.

\section{CONFLICT OF INTEREST}

The authors declare no conflict of interest.

\section{ACKNOWLEDGEMENTS}

We thank Royal National Orthopaedic Hospital Charity, UK.

1 Anderson KD. Targeting recovery: priorities of the spinal cord-injured population. J Neurotrauma 2004; 21: 1371-1383.

2 Wyndaele JJ. Conservative treatment. In: Corcos J, Schick E (eds). Evaluation and Treatment of the Neurogenic Bladder, 1st edn. Taylor \& Francis: London, UK, 2005 , pp 125-136.

3 McClurg D, Ashe RG, Marshall K, Lowe-Strong AS. Comparison of pelvic floor muscle training, electromyography biofeedback, and neuromuscular electrical stimulation for bladder dysfunction in people with multiple sclerosis: a randomized pilot study. Neurourol Urodyn 2006; 25: 337-348.

4 Laycock J. Clinical evaluation of the pelvic floor. In: Schussler B, Laycock J, Norton P, Stanton SI (eds). Pelvic Floor Re-education. Springer-Verlag: London, UK, 1994, pp 42-48.

5 Hagen S, Stark D, Glazener C. Individualised pelvic floor muscle training in women with pelvic organ prolapse: a multicentre randomised controlled trial. Lancet 2014; 383 . 796-806.

Supplementary Information accompanies this paper on the Spinal Cord website (http://www.nature.com/sc) 